\section{PROMPT MEDICAL ATTENDANCE ON THE POOR.}

ARRANGEIIENT WITH MEDICAL MEN, - PIAN AMONGST THE JEWS.

To the Editor of THE LANCET.

SIr:-The following case bringing forcibly to my mind some observations which I have seen in Tine LanceT, on the necessity of instant medical and surgical relief being afforded to the poor, in accidents, and other emergencies, I am induced to send you the case, with some observations which suggested themselves to my mind, on the mode of remunerating medical men for attendance upon the poor, which, although perhaps not the best that can be adopted, is, I think, infinitely preferable to the present degrading and unprofessional system of contract, or tender.

Jetween one and two o'clock, A.M., on Monday, December 11, last, as the policeman was going round his beat in Moor-lane, Cripplegate, he heard a cry of "Murder," followed by sounds of scuffing and quarrelling, at the house of Samuel Day, No. 19, in that street. He immediately informed his superintendant of the circumstance, and they knocked at the door, but it was some time before they could obtain entrance. When admitted they found that Day's daughter, a young girl twenty years of age, had just been delivered of a child, under very suspicious circumstances. The superintendant immediately sent the policeman for me, and I promptly attended, and rendered the unfortunate girl every necessary assistance. The mother of the girl had the infant, a well-grown female off'spring, in her lap. It was covered with filth and soil, and wrapped in an old flannel petticoat; the umbilical chord was broken off, and not tied; the placenta was not detached from the nterus.

The man, Day, states, that having heard his daughter get up and go into the yard, he followed her, and met her coming out of the closet. He inquired what was the matter, and she made him some evasive answer, but he thought that he heard the cry of a child, and upon going into the closet he perceived a full-grown infant struggling in the soil. He immediately rescned it from its perilous situation, and gave it in charge to his wife. No clothes had been provided for the child. Both mother and child are doing well. It would be premature to make any observation upon the conduct of the young woman, or her friends, as the matter is about to become the subject of judicial inquiry.

Now, under such circumstances as the above, and many others of daily occurrence, either a medical man's time and attention must be given gratuitously, according to the present state of the law, or lie must incur the moral responsibility of neglecting a fel- low-creature where he might be the means of saviag life. The plan which I would propose (in the absence of a better) to amend this is, that all the qualified medical men in a parish who are willing to undertake the charge of the poor, should, as a slight acknowledgment of their services, be exempted from contributing to the poor-rate, and that the labour should be divided equitably amongst them. Thus, if there are twelve medical men who are willing to act, each might take the duty for a month, in rotation, and he might then deliver up his cases to the gentleman whose turn it was to act next; or, if it should be considered improper to change the medical attendant on particular cases, the gentleman who first took them might continue to attend them until the patients recovered, and the gentleman next in rotation might take all fresh cases for a month, continuing to attend them until recovered.

The medical gentlemen should not provide medicines, but have their prescriptions dispensed by some druggist appointed by the parish, either by contract, at so much per prescription, or per case. I think also there would be no impropriety in a parish contracting with a druggist any more than with any other tradesman. Indeed, there would be no novelty in so doing, as this is done with the poor Jews, who belong to the Synagogue in Duke's-place. A medical gentleman is appointed by the managers of the synagogue to attend their poor, and his prescriptions are compounded by a respect. able druggist in Whitechapel, at so much per prescription, and this system is found to work extremely well.

I think that several good ends would be answered by this method. It would bring the medical men of a parish, or union, into friendly communion. Every man would be anxious to pay proper attention to his cases, as, by neglect, he would be brought into injurious comparison with his more attentive neighbour, and the poor would be properly attended, without the medical attendant being, as he now very often must be, out of pocket by doing his patient justice. Each medical man should agree to attend any case of emergency occurring in his neighbourhood, so that no delay might arise in procuring the necessary assistance, or in sending for the gentleman acting at the time, who would, however, take charge of the case as early as possible; medical neighbours so situated would be always ready to act for each other when unavoidably detained by their engagements elsewhere, or absent from illness. I feel no donbt that the above plan, with some modifications, would answer in the metropolitan parishes, if not in the country. I am, Sir, your obedient servant,

Thomas Lloyd, M.R.C.S. 1, New Basinghall-street, Dec. 13, 1837. 